Article

\title{
Safety of Multiple Vaccinations and Durability of Vaccine-Induced Antibodies in an Italian Military Cohort 5 Years after Immunization
}

\author{
Claudia Ferlito ${ }^{1,+}{ }^{+}$, Vincenzo Visco ${ }^{1,+} \mathbb{D}$, Roberto Biselli ${ }^{2,+}+$, Maria Sofia Cattaruzza ${ }^{3,+}$ (D), Giulia Carreras $4,+$, \\ Gerardo Salerno ${ }^{1,+}$, Florigio Lista ${ }^{5}$, Maria Rosaria Capobianchi ${ }^{6, \S}$, Concetta Castilletti ${ }^{6} \mathbb{D}$, Daniele Lapa ${ }^{6}$, \\ Guido Antonelli ${ }^{7}$, Massimo Gentile ${ }^{7}$, Maurizio Sorice ${ }^{8}$, Gloria Riitano ${ }^{8}$, Giuseppe Lucania ${ }^{8}$, Valeria Riccieri ${ }^{9}{ }^{(D)}$, \\ Fabrizio Mainiero ${ }^{8}$, Antonio Angeloni ${ }^{8}$, Marco Lucarelli ${ }^{8}{ }^{D}$, Giampiero Ferraguti ${ }^{8}$ (D), Alberto Autore ${ }^{10}$, \\ Marco Lastilla ${ }^{10}$, Simonetta Salemi ${ }^{1}$, Michela Ileen Biondo ${ }^{1}$, Andrea Picchianti-Diamanti ${ }^{1}$ D, Sara Caporuscio ${ }^{1}$, \\ Raffaela Teloni ${ }^{11}$, Sabrina Mariotti ${ }^{11}$, Roberto Nisini ${ }^{11, *,+}$ and Raffaele $D^{\prime}$ Amelio ${ }^{1,+}+$ (D)
}

1 Dipartimento di Medicina Clinica e Molecolare, Sapienza Università di Roma, Via di Grottarossa 1035-1039, 00189 Roma, Italy; clau.ferlito@gmail.com (C.F.); vincenzo.visco1@uniroma1.it (V.V.); gerardo.salerno@uniroma1.it (G.S.); simonetta.salemi@uniroma1.it (S.S.); biondo_michela@yahoo.it (M.I.B.); andrea.picchiantidiamanti@uniroma1.it (A.P.-D.); sara.caporuscio1@gmail.com (S.C.); raffaele.damelio@gmail.com (R.D.)

2 Ispettorato Generale della Sanità Militare, Stato Maggiore della Difesa, Via S. Stefano Rotondo 4, 00184 Roma, Italy; bobbiselli@libero.it

3 Dipartimento di Sanità Pubblica e Malattie Infettive, Sapienza Università di Roma, Piazzale Aldo Moro 5, 00185 Roma, Italy; mariasofia.cattaruzza@uniroma1.it

check for updates

Citation: Ferlito, C.; Visco, V.; Biselli, R.; Cattaruzza, M.S.; Carreras, G.; Salerno, G.; Lista, F.; Capobianchi, M.R.; Castilletti, C.; Lapa, D.; et al. Safety of Multiple Vaccinations and Durability of Vaccine-Induced Antibodies in an Italian Military Cohort 5 Years after Immunization. Biomedicines 2022, 10, 6. https://doi.org/10.3390/ biomedicines 10010006

Academic Editors: Janka Petravić and Dimiter S. Dimitrov

Received: 30 September 2021 Accepted: 16 December 2021 Published: 21 December 2021

Publisher's Note: MDPI stays neutral with regard to jurisdictional claims in published maps and institutional affiliations.

Copyright: (C) 2021 by the authors. Licensee MDPI, Basel, Switzerland. This article is an open access article distributed under the terms and conditions of the Creative Commons Attribution (CC BY) license (https:// creativecommons.org/licenses/by/ $4.0 /)$.
4 Istituto per lo Studio la Prevenzione e la Rete Oncologica, Via Cosimo il Vecchio 2, 50139 Firenze, Italy; g.carreras@ispro.toscana.it

5 Dipartimento Scientifico Policlinico Militare di Roma, Esercito Italiano, Via S. Stefano Rotondo 4, 00184 Roma, Italy; florigio.lista@esercito.difesa.it

6 Laboratorio di Virologia, IRCCS, Istituto Nazionale Malattie Infettive "Lazzaro Spallanzani" Via Portuense 292, 00149 Roma, Italy; maria.capobianchi@inmi.it (M.R.C.); concetta.castilletti@inmi.it (C.C.); daniele.lapa@inmi.it (D.L.)

7 Dipartimento di Medicina Molecolare, Sapienza Università di Roma, Viale di Porta Tiburtina 28, 00185 Roma, Italy; guido.antonelli@uniroma1.it (G.A.); massimo.gentile@uniroma1.it (M.G.)

8 Dipartimento di Medicina Sperimentale, Sapienza Università di Roma, AOU Policlinico Umberto I, Viale del Policlinico 155, 00161 Roma, Italy; maurizio.sorice@uniroma1.it (M.S.); gloria.riitano@uniroma1.it (G.R.); giuseppe.lucania@uniroma1.it (G.L.); fabrizio.mainiero@uniroma1.it (F.M.); antonio.angeloni@uniroma1.it (A.A.); marco.lucarellii@uniroma1.it (M.L.); giampiero.ferraguti@uniroma1.it (G.F.)

9 Dipartimento di Scienze Cliniche Internistiche, Anestesiologiche e Cardiovascolari, Sapienza Università di Roma, AOU Policlinico Umberto I, Viale del Policlinico 155, 00161 Roma, Italy; valeria.riccieri@uniroma1.it

10 Osservatorio Epidemiologico della Difesa, Ispettorato Generale della Sanità Militare, Stato Maggiore della Difesa, Via S. Stefano Rotondo 4, 00184 Roma, Italy; alberto.autore@aeronautica.difesa.it (A.A.); marco.lastilla@aeronautica.difesa.it (M.L.)

11 Dipartimento di Malattie Infettive, Istituto Superiore di Sanità, Viale Regina Elena 299, 00161 Roma, Italy; raffaela.teloni@iss.it (R.T.); sabrina.mariotti@iss.it (S.M.)

* Correspondence: roberto.nisini@iss.it; Tel.: +39-06-49902659

+ These authors contributed equally to this work.

$\ddagger$ Retired.

$\S$ Current affiliations: Saint Camillus International University of Health Sciences, Via di S. Alessandro 8, 00131 Roma, Italy; Department of Infectious Tropical Diseases and Microbiology, IRCCS Sacro Cuore Don Calabria Hospital, Via Don A. Sempreboni 5, 37024 Negrar di Valpolicella, Italy.

Abstract: We previously examined the safety and immunogenicity of multiple vaccines administered to a military cohort, divided into two groups, the first composed of students at military schools, thus operating inside the national borders for at least 3 years, and the other formed of soldiers periodically engaged in a 9-month-long mission abroad (Lebanon). In the current study, we analyzed 112 individuals of this cohort, 50 pertaining to the first group and 62 to the second group, in order to examine the possible late appearance of side effects and to calculate the half-life of the induced antibodies. Moreover, the possible involvement of B-cell polyclonal activation as a pathogenetic mechanism for long term antibody persistence has even been explored. No late side effects, as far 
as autoimmunity and/or lymphoproliferation appearance, have been noticed. The long duration of the vaccine induced anti-HAV antibodies has been confirmed, whereas the antibodies induced by tetravalent meningococcal polysaccharide vaccine have been found to persist above the threshold for putative protection for a longer time, and anti-tetanus, diphtheria, and polio 1 and 3 for a shorter time than previously estimated. No signs of polyclonal B-cell activation have been found, as a possible mechanism to understand the long antibody persistence.

Keywords: vaccines; safety; antibody durability; antibody persistence; B-cell polyclonal activation

\section{Introduction}

Military personnel are especially exposed to the risk of infectious diseases, due to their daily activity, which exposes them to trauma and contaminated wounds, and community life often in extremely unfavorable environmental conditions, thus they are required to have mandatory vaccinations all over the world [1]. The military, therefore, is the adult population with the highest experience of vaccinations. However, despite the undeniable merits that the military has in the prevention and control of infectious diseases, frequently even in favor of the general population, relatively few studies have been carried out on the possible reciprocal interference by contemporaneously administered multiple different vaccines regarding vaccine immunogenicity and effectiveness as well as on the possible induction of side effects. Such a relative scarcity of systematic studies has allowed that poorly understood phenomena, such as the Gulf War Syndrome in the USA [2], and the occurrence of lymphoproliferative diseases in the young military in Italy could be ascribed to a consequence of simultaneously administered multiple vaccinations [3].

In the attempt to provide a further contribution in this field, we analyzed a military cohort composed of two different groups, group 1 was formed of military students at the military schools, thus newly enrolled and vaccinated, and stably operating in the national borders for at least 3 years, corresponding to the minimum length of the training period, and group 2 of older military individuals, periodically engaged in a 9-month operational activity abroad (Lebanon). Previous studies have allowed establishing that no autoimmune/lymphoproliferative phenomena could be observed up to 9-month postvaccination in both groups [4]; moreover, the specific immune response to meningococcal tetravalent polysaccharide vaccine [5], tetanus/diphtheria [6] and viral vaccines, including hepatitis A virus (HAV), measles, mumps, and rubella (MMR), polio and influenza [7] was excellent and long durable.

The aim of the current study was the additional control of immune parameters after a longer follow-up to 5-year in some individuals of the cohort already studied and followedup to 9-month after a multiple vaccination schedule.

The possible appearance of late side effects has been investigated, as well as the duration of the antibody response at the putative protective level has been calculated and checked. Finally, the possible contribution of the B-cell polyclonal activation to the antibody level persistence has also been tested.

\section{Materials and Methods}

\subsection{Study Population}

As previously reported [4], from September 2012 to June 2014 two groups of Italian military personnel, the first (group 1) represented by newly recruited students at military schools residing in Italy for at least 3 years and the other (group 2) by soldiers operating abroad (Lebanon) for nine months, were enrolled. Exclusion criteria were pregnancy, immunodepression, vaccine hypersensitivity. For the parameters evaluated in the current study blood samples were collected in both groups in 2017. This time was denominated T3, and it was compared with the same parameters collected in the same subjects at T2 (nine months following the vaccine administration). 
The study was approved by the Italian Ministry of Defense ethical committee in July 2011 and registered in clinicaltrials.gov in 2012 with the identifier NCT01807780.

\subsection{Vaccination Schedule}

As previously reported [4], at enrollment, informed consent and the medical history of all individuals were collected. The vaccination schedule was personalized based on the history of infectious diseases and already received vaccinations; moreover, the vaccination schedule was even tailored on type of employment, either national or abroad. Typhoid vaccine was only administered to the military of group 2. Administered vaccines were the following: tetanus/diphtheria (Td, DifTetAll-Novartis Vaccines and Diagnostics, Siena, Italy), inactivated polio (Imovax polio-Sanofi Pasteur MSD SpA, Roma, Italy), measles/mumps/rubella (MMR, Priorix-GlaxoSmithKline SpA, Verona, Italy), chickenpox (Varivax-Sanofi Pasteur MSD SpA, Roma, Italy) polysaccharide tetravalent (A, $\mathrm{C}, \mathrm{W}_{135}, \mathrm{Y}$ ) meningococcal meningitis (Mencevax-Pzifer Srl, Latina, Italy), hepatitis A virus (HAV, Epaxal-Crucell Italy Srl, Baranzate, Italy), hepatitis B virus (HBV, Engerix B-GlaxoSmithKline SpA, Verona, Italy), influenza (Fluad-Seqirus Srl, Siena, Italy), and typhoid (Vivotif Berna-PaxVax Ltd., Birmingham, UK). Vaccines were generally administered the same day (in different arms), but in a few cases up to two weeks apart.

\subsection{Safety, Immunogenicity, and Effectiveness}

Vaccine safety was examined by the military monitoring system of vaccination adverse events and by the evaluation of the peripheral blood cell count, serum protein electrophoresis and serum immunoglobulins (Ig), to monitor the possible onset of signs suggestive of lymphoproliferative disorders, as previously reported [4]. Moreover, the search for autoantibodies (anti-nuclear [ANA], anti-double-stranded DNA [anti-dsDNA], anti-extractable nuclear antigens [anti-ENAs], anti-phospholipid [APL], anti-neutrophil cytoplasmic antibodies [ANCA] and rheumatoid factor [RF]), was performed. Immunogenicity was carried out by examining the levels of anti-vaccine antibodies. This further point was used in the calculation of the antibody duration above the putative threshold for protection. Lastly, effectiveness was determined through the military surveillance system by monitoring the number of cases of infectious diseases against which the vaccines should induce protection.

\subsection{Autoantibodies}

As previously reported [4], ANA, anti-dsDNA and ANCA were detected by indirect immunofluorescence (IIF), using Hep-2 cells, Crithidia luciliae slides, formalin- and ethanolfixed neutrophils as substrate, respectively. Titers $\geq 1: 80$ (for ANA), $\geq 1: 20$ (for antidsDNA) and $\geq 1: 20$ (for ANCA) were considered positive. Anti-ENAs were identified by ELISA (commercial kit ELISA QUANTA LiteTM-INOVA). Test results N20 IU/mL were considered positive. APL was analyzed by ELISA (commercial kit QUANTA Lite ACA IgM III, QUANTA Lite ACA IgG III). Test results N20 MPL or N20 GPL were considered positive.

\subsection{Specific Anti-Men-PsA, C, $W_{135}, Y$ Antibodies}

Specific antibodies were analyzed by enzyme-linked immunosorbent assay (ELISA), as previously reported [5]. Briefly, 96-well plates were coated with $100 \mu \mathrm{L} /$ well of $\mathrm{A}, \mathrm{C}, \mathrm{W}_{135}$, Y Men-Ps, kindly donated by Novartis Vaccines (now GSK), Siena, Italy, at a concentration of $10 \mu \mathrm{g} / \mathrm{mL}$ in phosphate-buffered saline (PBS) $\mathrm{pH} 8.2$ and incubated at $+4{ }^{\circ} \mathrm{C}$ overnight. After three washes with PBS supplemented with 0.005\% Tween 20 (TPBS), a blocking step of $100 \mu \mathrm{L} /$ well of TPBS with bovine serum albumin (BSA) $3 \%$ was performed for $1 \mathrm{~h}$ at $37^{\circ} \mathrm{C}$. After three more washes, $100 \mu \mathrm{L} /$ well of the samples and control serum [kindly donated by Novartis Vaccines (now GSK), Siena, Italy] diluted in TPBS 1:200 was incubated for $2 \mathrm{~h}$ at $37^{\circ} \mathrm{C}$. After three further washes, $100 \mu \mathrm{L} /$ well of the alkaline phosphatase-conjugated recognition antihuman immunoglobulin (Ig)G anti-serum diluted 1:1000 in TPBS were added for $1 \mathrm{~h}$ at $37^{\circ} \mathrm{C}$. Finally, $100 \mu \mathrm{L} /$ well of substrate (paranitrophenil phosphate $/ 5 \mathrm{~mL}$ carbonate-bicarbonate) were added and left at room temperature in the dark. The reaction 
was blocked by $\mathrm{NaOH} 3 \mathrm{M}$ and the absorbance read at $405 \mathrm{~nm}$. The concentration of Men-Ps-specific IgG in test sera was obtained by plotting the control serum dilutions (from 1:50 to $1: 6400)$ and the corresponding IgG concentration values $(\mu \mathrm{g} / \mathrm{mL})$. As the titer of serum bactericidal antibodies is considered the gold standard for meningococcal seroprotection and IgG ELISA values are considered a surrogate of protection [8], we defined the IgG concentration $\geq 2 \mu \mathrm{g} / \mathrm{mL}$ as a 'putative' seroprotective level [9-14]. The seroconversion, defined as a twofold increase in IgG concentrations from T0 to T2, was considered a measure to identify subject responders to vaccination or booster doses [9].

\subsection{Specific Anti-Tetanus/Diphtheria Antibodies}

As previously reported [6], serum antibodies were examined by enzyme-linked immunosorbent assay (ELISA) commercial kits: NovaLisaTM Clostridium tetani toxin IgGELISA and Corynebacterium diphtheriae toxin 5S-IgG plus-ELISA (NovaTech Immunodiagnostica $\mathrm{GmbH}$, Dietzenbach, Germany). Antibody concentrations $0.1 \mathrm{IU} / \mathrm{mL}$ were considered protective [15]. Subjects doubling the pre-vaccination antibody levels (ratio $\mathrm{T} 2 / \mathrm{T} 0 \geq 2$ ) were considered a responder.

\subsection{HAV Antibody Analysis}

As previously reported [7], for HAV antibody determination, a commercial ELISA kit was used: Enzygnost ${ }^{\circledR}$ Anti-HAV (Siemens Healthcare Diagnostics GmbH, Marburg, Germany). The quantitative cut-off value for seropositivity was $10 \mathrm{mIU} / \mathrm{mL}$ [16].

\subsection{Polio Antibody Analysis}

\subsubsection{Cells and Viruses}

As previously reported [7], Vero E6 cells (European Collection of Cell Cultures, Salisbury, UK) were maintained in Modified Eagle Medium (MEM) supplemented with 10\% heat inactivated fetal calf serum (FCS) (Gibco, Thermo-Fisher Scientific, Waltham, MA, USA) at $37{ }^{\circ} \mathrm{C}$ in a humidified atmosphere. In our assays, the two polioviruses Sabin serotypes 1 and 3 were used (kindly provided by Dr. Giovanni Rezza from the Istituto Superiore di Sanità, Rome, Italy). The virus stocks were propagated in Vero E6 cells and were harvested at $48 \mathrm{~h}$ post-infection when $70-80 \%$ of cell monolayers had been killed. After freezing and thawing three times, cell lysates were clarified by low-speed centrifugation, aliquoted, and stored at $-70^{\circ} \mathrm{C}$. The poliovirus Sabin type 1 virus stock was used for all the experiments at titered $107.850 \%$ tissue culture infectious doses per milliliter (TCID50/mL). The poliovirus Sabin type 3 virus stock was used for all the experiments at titered 106.5 TCID50/mL.

\subsubsection{Microneutralization Assay}

The presence of poliovirus-neutralizing antibodies was assessed according to WHO guidelines $[17,18]$. Briefly, all serum samples, stored at $-20{ }^{\circ} \mathrm{C}$ until use, were heat inactivated ( $56^{\circ} \mathrm{C}$ for $30 \mathrm{~min}$ ) and serially twofold diluted from 1:4 to 1:4096 in MEM containing 2\% heat-inactivated FCS (final volume: $50 \mathrm{~L}$ ) in 96-well plates. Each well dilution was challenged with $50 \mathrm{~L}$ of type 1 or type 3 poliovirus Sabin strain (100 TCID50 per well, 1 plate for each serotype of poliovirus) and incubated at $37^{\circ} \mathrm{C}$ for $2 \mathrm{~h}$ in a $\mathrm{CO}_{2}$ incubator. After this first incubation period, each serum/viruses mix was transferred onto 24-h-old Vero E6 cells in 96-well plates and incubated in a humidified $\mathrm{CO}_{2}$ incubator at $36{ }^{\circ} \mathrm{C}$ for 5 days. An in-house reference serum was included in each test run to control the reproducibility of results, a 1:4 dilution of each serum without virus was included for each serum tested to check serum toxicity, and challenging viruses were back titrated in each test run to control the TCID50 challenge dose. The neutralizing antibody titer of the serum against each type of poliovirus was determined as the endpoint dilution of the serum that inhibited the poliovirus infection, observed by the cytopathic effect of inoculated cells. The neutralizing antibody assay is the method of choice to determine the immune status against poliovirus. Although the precise antibody titer that is necessary for protection is unknown, 
it is accepted that 1:4-1:8 of type-specific neutralization of an infection in a cell culture is putatively protective [16]; however, in the current study, the more stringent cut-off of 1:8 was chosen [19]. Responders were defined as the subjects at least able to quadruplicate baseline antibody titer at T2 [20].

\subsection{Statistical Analysis}

Categorical variables were analyzed by Yates corrected, two tails, $\chi^{2}$ test, whereas demographic data (mean age) by Student's $t$-test [4]. Values of $p \leq 0.05$ were considered significant. Statistical analysis was performed using the program package GraphPad Prism version 5.0 (GraphPad Software Inc., San Diego, CA, USA).

Univariate and multivariate analyses were used to evaluate factors associated with outcomes and to adjust for the effect of confounders. Multiple regression analysis was used to evaluate the effects of demographic and immunization variables on the T3/T2 ratio (expressed as the natural logarithm) of lymphocytes, total serum proteins, IgM, and IgG. The R software (The R Foundation for Statistical Computing) was used.

The persistence of vaccine-induced antibodies above the putative threshold for protection has been calculated according to the formula published by Hammarlund et al.: $\log ($ anti-vaccine antigen antibody concentration $)=\alpha+\beta \times$ years $+\varepsilon$, where $\alpha$ represented mean $\log$ concentration at the time of vaccination; $\beta$ represented decay rate and $\varepsilon$ represented error term [21]. The decay rates $(\beta)$ was calculated by their regression model analysis with the following equation: $\beta=[\log ($ anti-vaccine antigen antibody concentration $)-\alpha-\varepsilon] /$ years and the half-life was calculated by their formula as $\log (0.5) / \beta$ [21]. The durability has been estimated by the intersection of the line calculated with the equation reported above with the line indicating the threshold for protection. The vaccine-induced antibody persistence above the threshold for putative protection $(2 \mu \mathrm{g} / \mathrm{mL}$ for meningococcal polysaccharides, $0.1 \mathrm{IU} / \mathrm{mL}$ for tetanus and diphtheria, $10 \mathrm{mIU} / \mathrm{mL}$ for $\mathrm{HAV}$, a 1:8 titer for polio type 1 and 3, thus using the reciprocal 8 as the cut-off) has been calculated based on the geometric mean concentrations (GMCs) at T3 and the half-lives. In particular, the relationship between half-life and durability has been calculated by the equation $d=n h$, where $d$ is durability in years, $h$ stands for half-life and $n$ is the folds half-life should be multiplied to reach the cut-off. The factor $n$ may be identified by the formula $\log _{2}(x)$, where $x$ is the ratio GMC/GMT at T3/cut-off for protection. Moreover, for further control, in meningococcal polysaccharide antigens, the vaccine-induced persistence of antibody level above the putative threshold for protection was also calculated (considering a linear mean decay) using the point of intersection of the line passing through the GMCs at T2 and T3 with the threshold line for protection. The equation of the line passing through the GMCs at T2 and T3 was calculated using the formula to calculate a line having two points: $\mathrm{GMC}_{\mathrm{T} 2}\left(\mathrm{x}_{1} ; \mathrm{y}_{1}\right)$ and $\mathrm{GMC}_{\mathrm{T} 3}\left(\mathrm{x}_{2} ; \mathrm{y}_{2}\right)$ : $\mathrm{y}-\mathrm{y}_{1}=\left[\left(\mathrm{y}_{2}-\mathrm{y}_{1}\right) /\left(\mathrm{x}_{2}-\mathrm{x}_{1}\right)\right] \times\left(\mathrm{x}-\mathrm{x}_{1}\right)$. Statistical analyses were performed by the $\mathrm{R}$ software (The R Foundation for Statistical Computing).

\section{Results}

Out of the military cohort originally enrolled between September 2012 and June 2014, the subjects here investigated were 112, 50 pertained to group 1, originally composed of military students, 38 males and 12 females, and 62 to the group 2, periodically engaged in a 9-month-long mission abroad (Lebanon), 60 males and 2 females (Table 1). The mean age \pm standard deviation (SD) of the subjects of group 1 was $25.88 \pm 2.13$, with a significant difference between males $(26.21 \pm 2.28)$ and females $(24.83 \pm 1.11, p<0.05)$, whereas the mean age \pm SD of the subjects of the group 2 was significantly higher compared to the group $1(34.67 \pm 4.55, p<0.0000001)$. No difference could be calculated for males and females of group 2, the latter being only 2 . 
Table 1. Demographic data of the military of group 1 and group 2.

\begin{tabular}{cccc}
\hline Military Subjects & N (\%) & M/F & Mean Age \pm SD \\
\hline Group 1 & $50(45)$ & $38 / 12^{\circ}$ & $25.88 \pm 2.13^{*}$ \\
\hline Group 2 & $62(55)$ & $60 / 2$ & $34.67 \pm 4.55$ \\
\hline Total & $112(100)$ & $98 / 14$ & $30.34 \pm 5.46$ \\
\hline${ }^{\circ}=0.002550$ vs. group $2{ }^{*} p<0.0000001$ vs. group 2. & &
\end{tabular}

The military of group 1 was only vaccinated at the time of enrolment (2012-2013), whereas 39/62 (63\%) group 2 subjects had received additional vaccine boosters in the period between T2 (9-month post-vaccination) and T3 (5-year post-vaccination). In particular, the 39 group 2 subjects received a variable number of boosters, which could range from 1 to 4 , so that cumulatively 14 tetanus/diphtheria, three meningococcal polysaccharides and eight meningococcal conjugated, $14 \mathrm{HAV}$, three $\mathrm{HBV}$ and 17 polio boosters, as well as nine oral live typhoid vaccines, have been administered in the period between $\mathrm{T} 2$ and $\mathrm{T} 3$ to these participants.

The results of non-specific parameters, such as lymphocytes, serum proteins and immunoglobulin levels at T3 compared with T2 are reported in Table 2 (upper part), whereas the relative multivariate analyses are reported in the lower part of the same Table for the subjects of group 1 and 2, respectively. Lymphocytes are significantly increased at T3 compared with T2 in group 1 in the univariate, however, this data is no more present in the multivariate analysis. Conversely, the multivariate analysis confirms the significant increase of IgM, dependent on the number of vaccines received between T2 and T3, in group 2.

No monoclonal peak in the electrophoretic pattern, nor autoimmune and/or lymphoproliferative disorders and neither other clinical adverse event have been noticed in this 5 -year period. No case of hepatitis A or meningococcal meningitis has been notified to the military surveillance system in these subjects.

Autoantibodies have been investigated in all subjects and found positive in eight; six were positive for ANA, at a titer of 1:80, excepting one who had 1:160, and 2 for low-level $\mathrm{RF}$ ( 21.3 and $33.9 \mathrm{IU} / \mathrm{mL}$, normal values $\leq 20 \mathrm{IU} / \mathrm{mL}$ ). Three subjects were already positive for ANA at T0 and T2 at the same titer, including the subject with the highest titer of 1:160, whereas for the other three subjects ANA positivity was new onset, as well as for RF. The difference between T2 and T3 was not significant (Table 3).

Twenty subjects were analyzed for anti-tetanus and anti-diphtheria antibodies; of these, $7 / 7(100 \%)$ of the group 1 and 12/13 (92\%) of the group 2 for tetanus and 4/7 $(57 \%)$ and $11 / 13(85 \%)$ for diphtheria, respectively, had antibodies higher than the putative threshold for protection of $0.1 \mathrm{IU} / \mathrm{mL}$. Out of the 60 subjects (27 of group 1 and 33 of group 2) analyzed for anti-meningococcal polysaccharide (menPs) antibodies, $27 / 27(100 \%)$ and $32 / 33$ (92\%) had anti-menPsA, 18/27 (67\%) and 23/33 (70\%) had anti-menPsC, $22 / 27(81 \%)$ and $20 / 33(61 \%)$ had anti-menPsW $135,25 / 27$ (93\%) and 25/33 (76\%) had anti-menPsY antibodies $\geq 2 \mu \mathrm{g} / \mathrm{mL}$, the putative threshold for protection. Out of the 32 subjects ( $25 \mathrm{of}$ group 1 and 7 of group 2) analyzed for anti-polio types 1 and 3 antibodies, 100\% in both groups had antibodies to both polio types above the putative threshold for protection (a titer $\geq 1: 8$ ). Finally, $24 / 25$ group 1 subjects had anti-HAV antibody levels above the putative threshold for protection of $10 \mathrm{mIU} / \mathrm{mL}$. The half-life, as well as the durability above the putative threshold for protection of vaccine-induced antibodies, have been investigated in these subjects. 
Table 2. Univariate analysis of mean values \pm SD of peripheral blood lymphocytes, serum protein and immunoglobulin measures at two time points in group 1 and 2 subjects, and Multivariate analysis of demographic and immunization variables on lymphocytes, total proteins, IgM, and IgG levels in both military groups.

\begin{tabular}{|c|c|c|c|c|c|c|c|c|c|c|c|c|c|c|c|c|}
\hline \multirow[t]{2}{*}{$\begin{array}{c}\text { Univariate } \\
\text { Analysis }\end{array}$} & \multicolumn{8}{|c|}{ Group 1} & \multicolumn{8}{|c|}{ Group 2} \\
\hline & $\underset{(\mathrm{mg} / \mathrm{dL})}{\mathrm{IgG}}$ & & $\underset{(\mathrm{mg} / \mathrm{dL})}{\mathrm{IgM}}$ & & $\underset{(\mathrm{mg} / \mathrm{dL})}{\mathrm{IgA}}$ & $\begin{array}{l}\text { Lymphocytes } \\
\text { (cells/ML) }\end{array}$ & $\begin{array}{c}\text { Total } \\
\text { Proteins } \\
\text { (g/dL) }\end{array}$ & & $\underset{(\mathrm{mg} / \mathrm{dL})}{\mathrm{IgG}}$ & & $\underset{\text { (mg/dL) }}{\mathrm{IgM}}$ & & $\underset{(\mathrm{mg} / \mathrm{dL})}{\mathrm{IgA}}$ & $\begin{array}{l}\text { Lymphocytes } \\
\text { (cells/ } / \mu \mathrm{L})\end{array}$ & $\begin{array}{l}\text { Total Proteir } \\
\text { (g/dL) }\end{array}$ & \\
\hline & \multicolumn{8}{|c|}{ Mean values \pm SD } & \multicolumn{8}{|c|}{ Mean values \pm SD } \\
\hline $\mathrm{T} 2$ & $1142 \pm 187$ & & $115 \pm 49$ & & $194 \pm 64$ & $1969 \pm 452$ & $8.03 \pm 1.05$ & & $1092 \pm 32$ & & $95 \pm 32$ & & $233 \pm 90$ & $2247 \pm 647$ & $6.29 \pm 0.35$ & \\
\hline T3 & $1095 \pm 287$ & & $115 \pm 40$ & & $199 \pm 76$ & $2255 \pm 529$ & $8.08 \pm 0.77$ & & $1051 \pm 28$ & & $128 \pm 60$ & & $242 \pm 87$ & $2398 \pm 591$ & $7.34 \pm 0.91$ & \\
\hline$p$ & ns & & ns & & ns & $<0.01$ & ns & & ns & & $<0.02$ & & $\mathrm{~ns}$ & ns & $<0.000001$ & \\
\hline \multirow{2}{*}{$\begin{array}{l}\text { Multivariate } \\
\text { Analysis }\end{array}$} & $\begin{array}{l}\text { IgG } \\
\left({ }^{\circ}\right)\end{array}$ & & $\begin{array}{l}\text { IgM } \\
\left({ }^{\circ}\right)\end{array}$ & & \multicolumn{2}{|c|}{ Lymphocytes $\left({ }^{\circ}\right)$} & \multicolumn{2}{|l|}{$\begin{array}{l}\text { Proteins } \\
\left({ }^{\circ}\right)\end{array}$} & $\begin{array}{l}\text { IgG } \\
\left({ }^{\circ}\right)\end{array}$ & & $\begin{array}{l}\text { IgM } \\
\left({ }^{\circ}\right)\end{array}$ & & \multicolumn{2}{|c|}{ Lymphocytes $\left({ }^{\circ}\right)$} & \multicolumn{2}{|l|}{$\begin{array}{c}\text { Proteins } \\
\left({ }^{\circ}\right)\end{array}$} \\
\hline & b-Coefficient & $p$ & b-Coefficient & $p$ & b-Coefficient & $p$ & b-Coefficient & $p$ & b-Coefficient & $p$ & b-Coefficient & $p$ & b-Coefficient & $p$ & b-Coefficient & $p$ \\
\hline Diftetal & 0.2442 & ns & -0.1851 & ns & 0.4117 & ns & 0.0296 & ns & -0.0520 & ns & -0.2864 & ns & 0.01530 & ns & -0.04774 & $\mathrm{~ns}$ \\
\hline Engerix & I & 1 & 1 & 1 & I & I & 1 & / & 0.0255 & ns & 0.1231 & $\mathrm{~ns}$ & -0.004031 & $\mathrm{~ns}$ & 1 & I \\
\hline Epaxal & 0.2025 & ns & 0.0004 & ns & 0.2857 & ns & 0.0260 & ns & 0.0645 & ns & -0.04155 & ns & 0.04929 & $\mathrm{~ns}$ & -0.0111 & ns \\
\hline Age & 0.0031 & ns & 0.0091 & ns & -0.0028 & ns & -0.0006 & ns & 0.0043 & ns & 0.008891 & ns & 0.000916 & ns & -0.0067 & ns \\
\hline Imovax polio & 0.4479 & 0.009 & -0.3151 & ns & 0.4282 & ns & 0.02207 & $\mathrm{~ns}$ & 0.08944 & ns & 0.05133 & $\mathrm{~ns}$ & 0.008030 & ns & 0.03883 & $\mathrm{~ns}$ \\
\hline Mencevax & 0.3139 & ns & -0.2176 & $\mathrm{~ns}$ & 0.09243 & ns & 0.02605 & $\mathrm{~ns}$ & -0.06887 & ns & -0.04949 & ns & -0.06048 & ns & 0.0329 & $\mathrm{~ns}$ \\
\hline $\mathrm{N}$ vax & -0.3036 & ns & 0.1956 & ns & -0.3932 & $\mathrm{~ns}$ & -0.04185 & ns & -0.04361 & $\mathrm{~ns}$ & 0.02901 & $\mathrm{~ns}$ & -0.02765 & $\mathrm{~ns}$ & -0.1037 & $\mathrm{~ns}$ \\
\hline $\mathrm{N}$ vax after $\mathrm{T} 2$ & I & I & I & 1 & I & I & 1 & 1 & -0.01710 & $\mathrm{~ns}$ & 0.1264 & 0.012 & -0.02657 & $\mathrm{~ns}$ & -0.0089 & $\mathrm{~ns}$ \\
\hline Priorix & -0.0650 & ns & 0.0954 & ns & 0.2247 & ns & 0.01782 & ns & I & I & I & I & I & I & I & I \\
\hline Varivax & 0.5520 & 0.009 & -0.0210 & ns & 0.4997 & ns & I & / & 0.01169 & ns & -0.2008 & ns & -0.04840 & ns & I & I \\
\hline Vivotif & / & / & / & / & / & / & / & / & 0.04287 & ns & 0.05843 & ns & -0.003886 & ns & -0.1020 & $\mathrm{~ns}$ \\
\hline
\end{tabular}

$\left({ }^{\circ}\right)$ Natural logarithm of the ratio (T3/T2). 
Table 3. Autoantibodies in 112 military subjects.

\begin{tabular}{cccc}
\hline Autoantibodies & $\mathbf{N}(\%)$ of Positive at T2 & $\mathbf{N}(\%)$ of Positive at T3 & $p$ \\
\hline ANA & $3(2.67)$ & $6(5.36)$ & NS \\
\hline RF & 0 & $2(1.78)$ & NS \\
\hline Total & $3(2.67)$ & $8(7.14)$ & NS \\
\hline
\end{tabular}

ANA = anti-nuclear antibodies; $\mathrm{RF}=$ rheumatoid factor.

The group 2 subjects were chosen among those who did not have received an additional booster of the specific vaccine between T2 and T3. The GMCs at three time points ( $\mathrm{T} 0=$ pre-vaccination, $\mathrm{T} 2=9$-month post-vaccination, $\mathrm{T} 3=5$-year post-vaccination) of the response to the tetravalent menPs vaccine, tetanus/diphtheria toxoids, $\mathrm{HAV}$, and polio 1 and 3, together with the T2/T0 and the T3/T2 ratios as well as the antibody persistence above the putative protective levels (assuming a linear decay) are reported in Table 4. Despite for menPs vaccine, the military of the two groups are presented separately, this is not the case for tetanus/diphtheria and polio, for which they are considered only one group, for the small dimensions of the sample, which do not allow to appreciate any significant difference between the two groups. The anti-menPsA in the group 2 and the anti-HAV antibody persistence could not be calculated, considering that the ratio $\mathrm{T} 3 / \mathrm{T} 2$ is $\geq 1$.

Table 4. Geometric mean concentrations of anti-meningococcal polysaccharides (menPs) A, C, $\mathrm{W}_{135}$, $\mathrm{Y}$, anti-tetanus, and diphtheria toxoids, anti-hepatitis A virus (HAV), and geometric mean titers of antipolio 1 and 3 in the military of both groups pre- (T0), 9-month (T2) and 5-year (T3) post-vaccination, as well as the T2/T0 and T3/T2 ratios, are reported. Half-life of vaccine-induced antibodies, with their $95 \%$ confidence interval (CI), as well as antibody durability above the putative threshold for protection in years are also indicated.

\begin{tabular}{|c|c|c|c|c|c|c|c|c|c|c|c|}
\hline \multirow{2}{*}{ Antigen } & \multirow{2}{*}{ Group } & \multirow{2}{*}{ T0 } & \multirow{2}{*}{$\mathrm{T} 2$} & \multirow{2}{*}{ T3 } & \multirow{2}{*}{ T2/T0 } & \multirow{2}{*}{ T3/T2 } & \multirow{2}{*}{$\begin{array}{c}\text { Half-Life } \\
\text { (Years) }\end{array}$} & \multirow{2}{*}{$95 \%$ CI } & \multicolumn{3}{|c|}{ Durability * } \\
\hline & & & & & & & & & A & B & C \\
\hline menPsA & 1 & 0.65 & 32.94 & 18.02 & 50.68 & 0.55 & 4.92 & $3.42-8.42$ & 15.60 & 20.60 & 9.30 \\
\hline menPsA & 2 & 4.93 & 27.44 & 28.60 & 5.56 & 1.04 & $\mathrm{NC}$ & $\mathrm{NC}$ & $\mathrm{NC}$ & $\mathrm{NC}$ & $\mathrm{NC}$ \\
\hline menPsC & 1 & 0.07 & 11.96 & 6.43 & 170.86 & 0.54 & 4.75 & $3.25-8.58$ & 8.00 & 13.00 & 8.40 \\
\hline menPsC & 2 & 9.11 & 15.49 & 4.97 & 1.70 & 0.32 & 2.58 & $2.00-3.58$ & 3.38 & 8.42 & 6.2 \\
\hline menPsW $_{135}$ & 1 & 0.37 & 5.83 & 3.06 & 15.76 & 0.52 & 4.50 & $2.67-15.00$ & 2.74 & 7.50 & 6.90 \\
\hline menPsW $_{135}$ & 2 & 5.91 & 9.85 & 3.50 & 1.67 & 0.35 & 2.83 & $2.17-4.25$ & 2.28 & 7.30 & 6.00 \\
\hline menPsY & 1 & 0.38 & 8.81 & 5.88 & 23.18 & 0.67 & 8.00 & $3.58-\infty$ & 12.40 & 17.08 & 11.20 \\
\hline menPsY & 2 & 3.38 & 13.56 & 2.12 & 4.01 & 0.15 & 1.58 & $1.17-2.50$ & 0.13 & 5.16 & 5.00 \\
\hline Tetanus & $1+2$ & 1.44 & 4.00 & 0.25 & 2.78 & 0.06 & 1.08 & $1.00-1.08$ & 1.43 & 6.42 & 5.00 \\
\hline Diphtheria & $1+2$ & 0.13 & 0.53 & 0.24 & 4.00 & 0.45 & 4.25 & $3.33-5.92$ & 3.15 & 11.58 & 7.00 \\
\hline Polio 1 & $1+2$ & 48.00 & 359.00 & 172.00 & 7.50 & 0.48 & 2.50 & $2.17-2.92$ & 11.00 & 17.33 & 8.70 \\
\hline Polio 3 & $1+2$ & 33.00 & 546.00 & 330.00 & 16.50 & 0.60 & 3.08 & $2.58-3.75$ & 16.53 & 23.25 & 11.30 \\
\hline HAV & 1 & 0.26 & 44.18 & 48.76 & 170.00 & 1.10 & $\mathrm{NC}$ & $\mathrm{NC}$ & $\mathrm{NC}$ & $\mathrm{NC}$ & $\mathrm{NC}$ \\
\hline
\end{tabular}

* The durability is expressed in years: in the column $\mathrm{A}$ it has been calculated by the equation $d=n h$, where $d$ is durability, $h$ stands for half-life and $n$ is the folds half-life should be multiplied for to reach the cut-off; in the column B by estimating the linear regression of the equation $\log ($ antibody titer $)=\alpha+\beta \times$ years $+\varepsilon$ and calculating the intersection with the line of the threshold for protection; in the column $C$ the durability has been estimated by the intersection of the line joining the geometric mean concentrations/titers at T2 (9-month) and T3 (5-year) with the line of the threshold for protection. $\mathrm{NC}=$ non-calculable.

Ten group 2 subjects, who had received at least one further booster of an adjuvanted vaccine between T2 and T3, except for MMR vaccine, were compared with 10 group 1 subjects, who did not have received any further booster in the period T2-T3; the ratio T3/T2 of antibodies addressed against measles, mumps and rubella was compared in 
the subjects of the two groups. No significant difference was observed for all the vaccine antigens tested (Table 5).

Table 5. Analysis of 10 subjects of group 2 who had received boosters of adjuvanted vaccines between $\mathrm{T} 2$ and $\mathrm{T} 3$ compared with 10 subjects of group 1 who did not receive boosters.

\begin{tabular}{ccccccc}
\hline Antigen & $\begin{array}{c}\text { Measles } \\
\text { T3/T2 }\end{array}$ & $\begin{array}{c}\text { Measles } \\
\text { T3/T2 }\end{array}$ & $\begin{array}{c}\text { Mumps } \\
\text { T3/T2 }\end{array}$ & $\begin{array}{c}\text { Mumps } \\
\text { T3/T2 }\end{array}$ & $\begin{array}{c}\text { Rubella } \\
\text { T3/T2 }\end{array}$ & $\begin{array}{c}\text { Rubella } \\
\text { T3/T2 }\end{array}$ \\
\hline Military group & 1 & 2 & 1 & 2 & 1 & 2 \\
\hline Subject 1 & 1.23 & 2.56 & 1.19 & 1.34 & 0.67 & 2.42 \\
\hline Subject 2 & 0.49 & 1.87 & 0.75 & 1.76 & 0.89 & 1.49 \\
\hline Subject 3 & 0.78 & 2.22 & 0.97 & 1.95 & 0.89 & 4.50 \\
\hline Subject 4 & 0.47 & 0.93 & 0.52 & 1.16 & 0.53 & 0.87 \\
\hline Subject 5 & 0.84 & 0.73 & 0.81 & 0.85 & 1.06 & 0.86 \\
\hline Subject 6 & 0.77 & 1.54 & 0.59 & 1.08 & 0.65 & 1.00 \\
\hline Subject 7 & 0.96 & 1.05 & 0.64 & 1.20 & 0.57 & 0.92 \\
\hline Subject 8 & 1.00 & 0.38 & 1.85 & 1.32 & 0.56 & 0.33 \\
\hline Subject 9 & 0.94 & 0.04 & 1.28 & 1.00 & 0.40 & 0.33 \\
\hline Subject 10 & 1.43 & 0.52 & 0.55 & 0.19 & 0.59 & 0.15 \\
\hline X $^{2}$ betwent
\end{tabular}

$\mathrm{X}^{2}$ between group 2 and group 1 by considering positive those with a T3/T2 $\geq 2$ = NS for all the vaccine antigens.

\section{Discussion}

The current study was carried out after a mean period of 5 years since multiple vaccinations of a cohort of military personnel. No late-appearing clinical side effect of autoimmune and/or lymphoproliferative disorders was observed during this long timeframe of followup, confirming our conclusions after a nine-month-long post-vaccination observation of the same cohort [4]. Positive autoantibodies have been found at low titer in eight individuals (six for ANA and two for RF), three of whom already positive at T0, with the same titer observed at T3. Out of the five individuals with new positivity, only one with a very slightly positive $\mathrm{RF}(21 \mathrm{IU} / \mathrm{mL}$, normal values $\leq 20 \mathrm{IU} / \mathrm{mL}$ ) had received four immunizations, even with adjuvanted vaccines, in the period between T2 and T3, thus in this subject only it may be hypothesized that immunization could, at least in part, be responsible for RF induction. Post-vaccine RF appearance has already been experimentally [22] and clinically [23] observed; it is generally transient and not associated with symptomatic autoimmune disease. In the remaining four subjects, the appearance of the autoantibody could not be associated with vaccination. They did not receive vaccinations in the period between $\mathrm{T} 2$ when they were negative, and T3. Thus, the positivity observed after 5 years should be ascribed to causes different from immunization, also considering that it is well known that the increased frequency of autoantibodies correlates with age [24], and it is not associated with autoimmune diseases. It should be emphasized that the possible dependence of autoimmunity from vaccinations is rarely documented and difficult to prove. A dependence has occasionally been suggested based on epidemiological observations, and frequently it was not confirmed by other studies. This is the case for the association HBV vaccine and multiple sclerosis [25-27] or type 1 diabetes and Haemophilus influenzae type b vaccine [28,29]. The associations between the vaccine against the human papillomavirus and autoimmune diseases, as well as the "autoimmune/autoinflammatory syndrome induced by adjuvants" (ASIA) have not been confirmed by meta-analytic studies [30,31]. Moreover, even for the association between autoimmune narcolepsy and pandemic influenza vaccine, although based on the demonstration of molecular mimicry [32], the alternative hypothesis of a direct viral cytopathic damage has been proposed $[33,34]$. Finally, the association between Guillain-Barré syndrome and the influenza vaccine [35], based on epidemiological observations [36], has not been systematically confirmed by subsequent studies [37]. Molecular 
mimicry represents the molecular basis for the association of infection/vaccination with autoimmunity. Molecular mimicry frequently occurs in nature, but control, homeostatic mechanisms prevent the development of clinical autoimmune diseases [38].

Lymphocytes, total serum proteins, and immunoglobulins, except for IgM, were not found elevated in group 2, in line with the absence of late side effects of vaccines. This observation is in line with previous reports by others [38] and confirms the results preliminarily described in this military cohort [4]. The significant increase of serum IgM, in association with the number of vaccine boosters received between T2 and T3, seems dependent on vaccine stimulation, as already observed [39], even though the increase is confined within physiological limits, likely transient, isolated, and apparently not associated to any pathology. In fact, no serum monoclonal gammopathy has been observed 5 years following the first study, despite the relatively high prevalence of the monoclonal gammopathy of undetermined significance (MGUS), which is $3 \%$ at 50 years of age, but with nearly one third estimated to have started 10-20 years before, as well as the well-known direct correlation between increased frequency of monoclonal gammopathy and increasing age [40]. Moreover, the total cohort here studied is not so small to prevent that at least one case be identified, especially because the stimuli able to induce MGUS are not well known, but an abnormal response to antigenic stimulation is nearly always present in the natural history of these patients [41].

The opportunity of studying this cohort of military personnel 5 years following multiple immunizations has also allowed calculating the half-life of the post-vaccine induced antibodies, with the consequent estimation of the antibody persistence above the putative threshold for protection. According to Amanna et al., who have carefully and deeply studied the issue of the behavior and durability of the antibody response to infections/vaccines, general kinetics of the antibody response is represented by a quick antibody decrease in the first $2-3$ years since infection/vaccination, followed by a marked slowed down decrease thereafter in a slow descending or linear plateau [42]. The current study, by adding a new distant point to the monitoring of post-vaccine antibody levels, has allowed to better calculate the durability of vaccine-induced antibodies. In fact, this has been analyzed not only with the method of Hammarlund et al. [21], which has already been used in the published studies of this cohort [5-7] but it was also estimated (considering a linear decay) by the study of the slope of the line passing through the GMCs at T2 and T3 and the point of the intersection with the threshold line for protection. The analysis with the method of Hammarlund et al. has been calculated in two ways, as described in materials and methods. The different methods provided similar results showing an increased estimation of durability for menPs antibodies compared with our previous study [5], and a reduced estimation for tetanus, diphtheria [6], and polio 1 and 3 [7]. However, the persistence of anti-menPsA antibodies in the subjects of group 2 and of anti-HAV in those immunized with the HAV vaccine could not be calculated, because the respective curves were slightly ascending.

In our previous study, the calculated half-lives of post-vaccine anti-menPsA, C, $\mathrm{W}_{135}$, and $\mathrm{Y}$ antibodies, were 1,1.12, 0.91 and 1.24 years, respectively, and able to assure an antibody persistence above the putative threshold for protection ranging from 2.5 to 4.5 years [5]. In the current study, half-lives were recalculated with antibody titers measured after 5 years and found even higher, ranging from less than 2 to 8 years for different menPs and the calculated durabilities are comparable between the two methods, the first one investigating the intersection of the line of decay with the line of cut-off and the other calculating the durability from the knowledge of antibody half-life. These data are in line with the rare, published results $[43,44]$, where the antibody durability has been either directly observed [43] or calculated with the linear regression [44]. Such a long persistence of the antibody response to polysaccharide antigens is quite surprising, considering that they are T-independent antigens unable to receive T-cell help to amplify the immune response and unable to induce memory B cells [45]. Consequently, repeated immunizations should represent brand new vaccinations and not boosters, thus carrying the risk of always recruiting new clones, which may first be expanded then induced to die for apoptosis, eventually 
creating the theoretical conditions for a repertoire impoverishment [46]. Thus, it seems very important to have confirmed an antibody persistence longer than the time of 3-5 years generally recommended for a new vaccine administration and calculated such persistence like the few studies on this topic $[43,44]$. Avoiding unnecessary boosters may contribute to maintaining the vaccine-induced antibody protection and reduce the vaccination schedules costs. The impossibility to calculate the duration of the anti-menPsA antibodies in group 2 may be a consequence of the cross-reactivity of menPsA with the polysaccharide antigens of Escherichia coli [47] and of Bacillus pumilus [48], which not-specifically may expand the immune response independently of the encounters with Neisseria meningitidis A, thus shaping the curve of antibody decrease linear or slightly ascending. Although the ELISA test is considered a less faithful expression of protection than the serum bactericidal titer, in adults the two assays have shown a correlation for menPsC and menPsW I35 $_{13}$ but not for menPsA and menPsY [44]. Conversely, the results for the persistence of anti-tetanus toxoid and anti-diphtheria antibodies (5-6 years and 7-11, respectively) are unexpected in the light of our previous study, in which the calculation estimated persistence of 65 and 20 years for tetanus and diphtheria, respectively. The two methods based on the direct analysis of durability provided more similar and probably reliable, data compared with the method based on the identification of antibody half-life to calculate durability, in which the values were markedly low. It is not easy to provide an explanation for the discrepancy between the previous and the current study and further studies on larger populations may provide definitive data. The estimation of anti-polio antibody persistence is lower than previously observed [7], whereas for HAV the long persistence is confirmed. The long persistence of anti-HAV antibodies may be a consequence of the high immunogenicity of the HAV vaccine, but possible natural boosters cannot be excluded, since HAV is still circulating in Italy [7].

The long persistence of antibodies at putative protective levels in the absence of antigen persistence is an immunology conundrum for which different interpretations have been suggested, such as the polyclonal activation of memory B cells model, the plasma cells niche competition model, and the plasma cells imprinted lifespan model [49]. Among these, the polyclonal B cell activation theory has been proposed many times, even though the formal evidence of this mechanism is poor and only described in single case reports [50]. We had already the opportunity to explore this possible mechanism of memory maintaining in 56 individuals of our military cohort, not recently boosted for tetanus/diphtheria toxoids but recently boosted with other not correlated vaccines and analyzed with anti-diphtheria antibodies only, as a read-out system, considering that anti-tetanus antibodies may be influenced by possible accesses to the emergency room. The results did not support the thesis, since in only $4 / 56$ subjects (7\%) the specific antibodies were doubled compared to T0 levels [6]. In the current study we wanted to deepen this topic, by comparing the response to measles, mumps, and rubella antigens in 10 subjects who had, and 10 subjects who had not, received vaccine boosters other than MMR between T2 and T3. The comparative analysis did not show any significant difference between the two groups. Despite menPs vaccines are considered unable to induce memory B-cells, the immune response to this vaccine we previously observed allowed us to hypothesize that memory B-cells could actually have been induced [5], thus we decided to monitor the response to menPsA, $\mathrm{C}, \mathrm{W}_{135}$ and $\mathrm{Y}$ in 11 subjects who had received vaccine boosters other than tetravalent menPs vaccine between T2 and T3, compared with 11 control subjects. Even in this case, no evidence of polyclonal B cell activation has been observed. Even if the number of analyzed cases is limited, it seems that polyclonal activation of memory B-cells is at least not frequently involved in maintaining post-vaccine antibody levels in normal adult people who had received multiple immunizations with these traditional vaccines. This result agrees with what has been observed by Amanna et al. [51] on four adults, who received a smallpox vaccine booster and have been monitored for one year post-vaccination for pre-existing antibodies against nine antigens (vaccinia, tetanus, diphtheria, and pertussis 
toxoids, measles, mumps, rubella, varicella, and Epstein Barr virus). Vaccinia antibodies did increase 8-80-fold, while antibodies against the other eight antigens did not.

The strength of this study is that we have confirmed the lack of late clinical and laboratory side effects in a military cohort followed up for 5 years from vaccinations and calculated the persistence of vaccine-induced antibodies at putative protective levels, confirming a theoretical quite long, sometimes life-long, protection towards the different vaccine antigens, including the menPs vaccine antigens, for which values higher than previously identified have been calculated [5]. The documented safety at 5-year postvaccination is a relevant message, considering the scarcity of systematic studies on such topic, and particularly in the current pandemic period, in which the fear of late side-effects by anti-coronavirus disease (COVID)-19 vaccines in a significant percentage of the global general population risks hindering or slowing down public health interventions. The main weakness is related to the absence of blood samples to be tested at different times, to make the calculation of the post-vaccine antibody durability more precise.

In conclusion, it is confirmed that multiple vaccinations in the military are not accompanied by side effects characterized by autoimmunity/lymphoproliferation, irrespective of the type of operativity, even at 5 years since multiple immunizations. The calculated vaccine-induced antibody durability is quite long, also in response to vaccines composed of T-independent antigens, unable to induce memory cells, such as menPs vaccine. Such a long antibody persistence does not seem to be a consequence of a polyclonal B cell activation.

Author Contributions: C.F., R.B., V.V., F.L., M.S.C., R.N. and R.D. designed and organized the study, analyzed and interpreted the results and drafted the manuscript; M.R.C., C.C. and D.L. carried out the serology and interpretation for anti-poliovirus types 1 and 3; G.A. and M.G. managed the MMR and HAV serology and interpretation; F.M. analyzed and interpreted the serum IgG, $\operatorname{IgA}$ and IgM; A.A. (Antonio Angeloni), M.L. (Marco Lucarelli) and G.F. analyzed and interpreted the serum protein electrophoresis; M.S., G.R., G.L. and V.R. analyzed and interpreted the autoantibodies; M.I.B., R.T., S.M., A.P.-D., S.S., S.C. and A.A. (Alberto Autore) coordinated the biological sample collection and distribution among the different collaborating laboratories, as well as the database organization; G.S. carried out the multivariate analysis and G.C. performed the calculations of antibody duration; A.A. (Alberto Autore) and M.L. (Marco Lastilla), as staff members of the Defense Epidemiological Observatory, collected and provided any clinical information on all the military personnel participating in the study. All of the authors have substantively revised the work and approved the submitted version (and the version substantially edited by journal staff that involves the authors' contributions to the study) and have agreed to be personally accountable for the authors' own contributions and for ensuring that questions related to the accuracy or integrity of any part of the work, even ones in which the author was not personally involved, are appropriately investigated, resolved, and documented in the literature. All authors have read and agreed to the published version of the manuscript.

Funding: This research was funded by the Italian Ministry of Defense (project grant application: M_DSSMD REG2016 003481309032016 ).

Institutional Review Board Statement: The study was conducted in accordance with the Declaration of Helsinki, and the protocol was approved by the Ethics Committee of the Italian Ministry of Defense in July 2011 and registered on clinicaltrials.gov in 2012 with the identifier NCT01807780.

Informed Consent Statement: All subjects gave their informed consent for inclusion before they participated in the study.

Data Availability Statement: Data supporting reported results may be found at Sapienza, Università di Roma, Dipartimento di Medicina Clinica e Molecolare, Dipartimento di Medicine Molecolare, Dipartimento di Medicina Sperimentale, Dipartimento di Sanità Pubblica e Malattie Infettive, at Istituto Superiore di Sanità, Dipartimento di Malattie Infettive, Parassitarie e Immuno-mediate and at Laboratorio di Virologia, IRCCS, Istituto Nazionale Malattie Infettive “Lazzaro Spallanzani”. 


\begin{abstract}
Acknowledgments: We thank Francesco Simonetti, Gennaro Banchini, Egidio Fracasso, Luigi Morgera, Fernando Murru, Claudio De Angelis, Mario Stefano Peragallo, Donato Pompeo De Cesare, Francesco Borelli, Salvatore Scandale, Giuseppe De Lorenzo, Raffaele Vento, Angelo Di Pietro (deceased), Antonio Rossi, Federico Sabatini, and Francesco Piccolo for their constant support and the military personnel who voluntarily accepted to participate in the study. Moreover, we thank Gabriella Cavalieri, Loredana Cataluffi and Marina Stefanelli for their precious technical support, the first two for carrying out immunofluorescence tests for autoantibodies and the last one for performing serum protein electrophoresis.
\end{abstract}

Conflicts of Interest: The authors declare no conflict of interest.

\title{
References
}

1. D'Amelio, R.; Heymann, D.L. Can the military contribute to global surveillance and control of infectious diseases? Emerg. Infect. Dis. 1998, 4, 704-705. [CrossRef]

2. Sartin, J.S. GulfWar Illnesses: Causes and Controversies. Mayo Clin. Proc. 2000, 75, 811-819. [CrossRef]

3. Tafuri, S.; Germinario, C. About the decision by the court of Ferrara on the supposed connection between the role of vaccination and the genesis of non-Hodgkin lymphoma. Ann. Ig. 2014, 26, 190-191.

4. Ferlito, C.; Barnaba, V.; Abrignani, S.; Bombaci, M.; Sette, A.; Sidney, J.; Biselli, R.; Tomao, E.; Cattaruzza, M.S.; Germano, V.; et al. Lack of evidence for post-vaccine onset of autoimmune/lymphoproliferative disorders, during a nine-month follow-up in multiply vaccinated Italian military personnel. Clin. Immunol. 2017, 181, 60-66. [CrossRef]

5. $\quad$ Ferlito, C.; Biselli, R.; Cattaruzza, M.S.; Teloni, R.; Mariotti, S.; Tomao, E.; Salerno, G.; Peragallo, M.S.; Lulli, P.; Caporuscio, S.; et al. Immunogenicity of meningococcal polysaccharide ACWY vaccine in primary immunized or revaccinated adults. Clin. Exp. Immunol. 2018, 194, 361-370. [CrossRef] [PubMed]

6. Ferlito, C.; Biselli, R.; Mariotti, S.; von Hunolstein, C.; Teloni, R.; Ralli, L.; Pinto, A.; Pisani, G.; Tirelli, V.; Biondo, M.I.; et al. Tetanus-diphtheria vaccination in adults: The long-term persistence of antibodies is not dependent on polyclonal B-cell activation and the defective response to diphtheria toxoid re-vaccination is associated to HLADRB1*01. Vaccine 2018, 36, 6718-6725. [CrossRef]

7. Ferlito, C.; Biselli, R.; Visco, V.; Cattaruzza, M.S.; Capobianchi, M.R.; Castilletti, C.; Lapa, D.; Nicoletti, L.; Marchi, A.; Magurano, F.; et al. Immunogenicity of Viral Vaccines in the Italian Military. Biomedicines 2021, 9, 87. [CrossRef] [PubMed]

8. Frasch, C.E.; Borrow, R.; Donnelly, J. Bactericidal antibody is the immunologic surrogate of protection against meningococcal disease. Vaccine 2009, 27 (Suppl. 2), B112-B116. [CrossRef] [PubMed]

9. Broderick, M.P.; Romero-Steiner, S.; Rajam, G.; Johnson, S.E.; Milton, A.; Kim, E.; Choi, L.J.; Radin, J.M.; Schmidt, D.S.; Carlone, G.M.; et al. Immune Responses in U.S. Military Personnel Who Received Meningococcal Conjugate Vaccine (MenACWY) Concomitantly with Other Vaccines Were Higher than in Personnel Who Received MenACWY Alone. Clin. Vaccine Immunol. 2016, 23, 672-680. [CrossRef]

10. Maslanka, S.E.; Tappero, J.W.; Plikaytis, B.D.; Brumberg, R.S.; Dykes, J.K.; Gheesling, L.L.; Donaldson, K.B.; Schuchat, A.; Pullman, J.; Jones, M.; et al. Age-dependent Neisseria meningitidis serogroup C class-specific antibody concentrations and bactericidal titers in sera from young children from Montana immunized with a licensed polysaccharide vaccine. Infect. Immun. 1998, 66, 2453-2459. [CrossRef]

11. Peltola, H.; Mäkelä, H.; Käyhty, H.; Jousimies, H.; Herva, E.; Hällström, K.; Sivonen, A.; Renkonen, O.V.; Pettay, O.; Karanko, V.; et al. Clinical efficacy of meningococcus group a capsular polysaccharide vaccine in children three months to five years of age. $N$. Engl. J. Med. 1977, 297, 686-691. [CrossRef]

12. Makela, P.H.; Kayhty, H.; Weckstrom, P.; Sivonen, A.; Renkonen, O.V. Effect of group-A meningococcal vaccine in army recruits in Finland. Lancet 1975, 2, 883-886. [CrossRef]

13. Dbaibo, G.; Van der Wielen, M.; Reda, M.; Medlej, F.; Tabet, C.; Boutriau, D.; Sumbul, A.; Anis, S.; Miller, J.M. The tetravalent meningococcal serogroups A, C, W-135, and Y tetanus toxoid conjugate vaccine is immunogenic with a clinically acceptable safety profile in subjects previously vaccinated with a tetravalent polysaccharide vaccine. Int. J. Infect. Dis. 2012, 16, e608-e615. [CrossRef]

14. Mueller, J.E.; Yaro, S.; Traore, Y.; Sangare, L.; Tarnagda, Z.; Njanpop-Lafourcade, B.M.; Borrow, R.; Gessner, B.D. Neisseria meningitidis serogroups A and W-135: Carriage and immunity in Burkina Faso, 2003. J. Infect. Dis. 2006, 193, 812-820. [CrossRef] [PubMed]

15. Schröder, J.P.; Kuhlmann, W.D. Tetanus immunity in men and women in the Federal Republic of Germany. Immun. Infekt. 1991, $19,14-17$.

16. Plotkin, S.A. Correlates of vaccine-induced immunity. Clin. Infect. Dis. 2008, 47, 401-409. [CrossRef]

17. World Health Organization. Manual of Laboratory Methods for Potency Testing of Vaccines Used in the WHO Expanded Programme on Immunization; WHO Publication No. WHO/BLG/95.1; World Health Organization: Geneva, Switzerland, 1995.

18. World Health Organization. Manual for the Virological Investigation of Polio; WHO/EPI/GEN/97.01; World Health Organization: Geneva, Switzerland, 1997. 
19. World Health Organization. Guidelines for WHO/EPI Collaborative Studies on Poliomyelitis. Standard Procedure for Determining Immunity to Poliovirus Using the Microneutralization Test; WHO/EPI/GEN/93.9; World Health Organization: Geneva, Switzerland, 1993.

20. Van Damme, P.; De Coster, I.; Bandyopadhyay, A.S.; Revets, H.; Withanage, K.; De Smedt, P.; Suykens, L.; Oberste, M.S.; Weldon, W.C.; Costa-Clemens, S.A.; et al. The safety and immunogenicity of two novel live attenuated monovalent (serotype 2) oral poliovirus vaccines in healthy adults: A double-blind, single-centre phase 1 study. Lancet 2019, 394, 148-158. [CrossRef]

21. Hammarlund, E.; Thomas, A.; Poore, E.A.; Amanna, I.J.; Rynko, A.E.; Mori, M.; Chen, Z.; Slifka, M.K. Durability of vaccineinduced immunity against tetanus and diphtheria toxins: A cross-sectional analysis. Clin. Infect. Dis. 2016, 62, 1111-1118. [CrossRef] [PubMed]

22. Nemazee, D.A.; Sato, V.L. Induction of rheumatoid antibodies in the mouse regulated production of autoantibody in the secondary humoral response. J. Exp. Med. 1983, 158, 529-545. [CrossRef] [PubMed]

23. D'Amelio, R.; Tagliabue, A.; Nencioni, L.; Di Addario, A.; Villa, L.; Manganaro, M.; Boraschi, D.; Le Moli, S.; Nisini, R.; Matricardi, P.M. Comparative analysis of immunological responses to oral (Ty21a) and parenteral (TAB) typhoid vaccines. Infect. Immun. 1988, 56, 2731-2735. [CrossRef] [PubMed]

24. Moulias, R.; Proust, J.; Wang, A.; Congy, F.; Marescot, M.R.; Deville Chabrolle, A.; Paris Hamelin, A.; Lesourd, B. Age-related increase in autoantibodies. Lancet 1984, 1, 1128-1129. [CrossRef]

25. Tourbah, A.; Gout, O.; Liblau, R.; Lyon-Caen, O.; Bougniot, C.; Iba-Zizen, M.T.; Cabanis, E.A. Encephalitis after hepatitis B vaccination: Recurrent disseminated encephalitis or MS? Neurology 1999, 53, 396-401. [CrossRef]

26. Confavreux, C.; Suissa, S.; Saddier, P.; Bourdes, V.; Vukusic, S. Vaccinations and the risk of relapse in multiple sclerosis. Vaccines in Multiple Sclerosis Study Group. N. Engl. J. Med. 2001, 344, 319-326. [CrossRef] [PubMed]

27. Ascherio, A.; Zhang, S.M.; Hernán, M.A.; Olek, M.J.; Coplan, P.M.; Brodovicz, K.; Walker, A.M. Hepatitis B vaccination and the risk of multiple sclerosis. N. Engl. J. Med. 2001, 344, 327-332. [CrossRef] [PubMed]

28. Classen, J.B.; Classen, D.C. Immunization in the first month of life may explain decline in incidence of IDDM in The Netherlands. Autoimmunity 1999, 31, 43-45. [CrossRef] [PubMed]

29. Karvonen, M.; Cepaitis, Z.; Tuomilehto, J. Association between type 1 diabetes and Haemophilus influenzae type b vaccination: Birth cohort study. BMJ 1999, 318, 1169-1172. [CrossRef]

30. Genovese, C.; La Fauci, V.; Squeri, A.; Trimarchi, G.; Squeri, R. HPV vaccine and autoimmune diseases: Systematic review and meta-analysis of the literature. J. Prev. Med. Hyg. 2018, 59, E194-E199.

31. Elwood, J.M.; Ameratunga, R. Autoimmune diseases after hepatitis B immunization in adults: Literature review and metaanalysis, with reference to 'autoimmune/autoinflammatory syndrome induced by adjuvants' (ASIA). Vaccine 2018, 36, 5796-5802. [CrossRef]

32. Ahmed, S.S.; Volkmuth, W.; Duca, J.; Corti, L.; Pallaoro, M.; Pezzicoli, A.; Karle, A.; Rigat, F.; Rappuoli, R.; Narasimhan, V.; et al. Antibodies to influenza nucleoprotein cross-react with human hypocretin receptor 2. Sci. Transl. Med. 2015, 7, $294 \mathrm{ra105.}$ [CrossRef] [PubMed]

33. Tesoriero, C.; Codita, A.; Zhang, M.D.; Cherninsky, A.; Karlsson, H.; Grassi-Zucconi, G.; Bertini, G.; Harkany, T.; Ljungberg, K.; Liljeström, P.; et al. H1N1 influenza virus induces narcolepsy-like sleep disruption and targets sleep-wake regulatory neurons in mice. Proc. Natl. Acad. Sci. USA 2016, 113, E368-E377. [CrossRef]

34. Schrauwen, E.J.; Herfst, S.; Leijten, L.M.; van Run, P.; Bestebroer, T.M.; Linster, M.; Bodewes, R.; Kreijtz, J.H.; Rimmelzwaan, G.F.; Osterhaus, A.D.; et al. The multibasic cleavage site in H5N1 virus is critical for systemic spread along the olfactory and hematogenous routes in ferrets. J. Virol. 2012, 86, 3975-3984. [CrossRef]

35. Marks, J.S.; Halpin, T.J. Guillain-Barre syndrome in recipients of A/New Jersey 'influenza vaccine. JAMA 1980, 243, 2490-2494. [CrossRef] [PubMed]

36. Langmuir, A.D.; Bregman, D.J.; Kurland, L.T.; Nathanson, N.; Victor, M. An epidemiologic and clinical-evaluation of GuillainBarre-syndrome reported in association with the administration of swine influenza vaccines. Am. J. Epidemiol. 1984, 119, 841-879. [CrossRef]

37. Principi, N.; Esposito, S. Do Vaccines Have a Role as a Cause of Autoimmune Neurological Syndromes? Front. Public Health 2020, 8, 361. [CrossRef]

38. Wraith, D.C.; Goldman, M.; Lambert, P.H. Vaccination and autoimmune disease: What is the evidence? Lancet 2003, 362, 1659-1666. [CrossRef]

39. Rager-Zisman, B.; Bazarsky, E.; Skibin, A.; Chamney, S.; Belmaker, I.; Shai, I.; Kordysh, E.; Griffin, D.E. The effect of measlesmumps-rubella (MMR) immunization on the immune responses of previously immunized primary school children. Vaccine 2003, 21, 2580-2588. [CrossRef]

40. Therneau, T.M.; Kyle, R.A.; Melton, L.J., 3rd; Larson, D.R.; Benson, J.T.; Colby, C.L.; Dispenzieri, A.; Kumar, S.; Katzmann, J.A.; Cerhan, J.R.; et al. Incidence of monoclonal gammopathy of undetermined significance and estimation of duration before first clinical recognition. Mayo Clin. Proc. 2012, 87, 1071-1079. [CrossRef]

41. Rajkumar, S.V. Prevention of progression in monoclonal gammopathy of undetermined significance. Clin. Cancer Res. 2009, 15, 5606-5608. [CrossRef]

42. Amanna, I.J.; Carlson, N.E.; Slifka, M.K. Duration of humoral immunity to common viral and vaccine antigens. N. Engl. J. Med. 2007, 357, 1903-1915. [CrossRef] 
43. Zangwill, K.M.; Stout, R.W.; Carlone, G.M.; Pais, L.; Harekeh, H.; Mitchell, S.; Wolfe, W.H.; Blackwood, V.; Plikaytis, B.D.; Wenger, J.D. Duration of Antibody Response after Meningococcal Polysaccharide Vaccination in US Air Force Personnel. J. Infect. Dis. 1994, 169, 847-852. [CrossRef]

44. Elias, J.; Findlow, J.; Borrow, R.; Tremmel, A.; Frosch, M.; Vogel, U. Persistence of antibodies in laboratory staff immunized with quadrivalent meningococcal polysaccharide vaccine. J. Occup. Med. Toxicol. 2013, 8, 4. [CrossRef]

45. Shapiro, E.D.; Berg, A.T.; Austrian, R.; Schroeder, D.; Parcells, V.; Margolis, A.; Adair, R.K.; Clemens, J.D. The protective efficacy of polyvalent pneumococcal polysaccharide vaccine. N. Engl. J. Med. 1991, 325, 1453-1460. [CrossRef]

46. Clutterbuck, E.A.; Lazarus, R.; Yu, L.M.; Bowman, J.; Bateman, E.A.; Diggle, L.; Angus, B.; Peto, T.E.; Beverley, P.C.; Mant, D.; et al. Pneumococcal conjugate and plain polysaccharide vaccines have divergent effects on antigen-specific B cells. J. Infect. Dis. 2012, 205, 1408-1416. [CrossRef]

47. Guirguis, N.; Schneerson, R.; Bax, A.; Egan, W.; Robbins, J.B.; Shiloach, J.; Orskov, I.; Orskov, F.; El Kholy, A. Escherichia coli K51 and K93 capsular polysaccharides are crossreactive with the group A capsular polysaccharide of Neisseria meningitidis. Immunochemical, biological, and epidemiological studies. J. Exp. Med. 1985, 162, 1837-1851. [CrossRef] [PubMed]

48. Vann, W.F.; Liu, T.Y.; Robbins, J.B. Bacillus pumilus polysaccharide crossreactive with meningococcal group A polysaccharide. Infect. Immun. 1976, 13, 1654-1662. [CrossRef] [PubMed]

49. Amanna, I.J.; Slifka, M.K. Mechanisms that determine plasma cell lifespan and the duration of humoral immunity. Immunol. Rev. 2010, 236, 125-138. [CrossRef] [PubMed]

50. Bernasconi, N.L.; Traggiai, E.; Lanzavecchia, A. Maintenance of serological memory by polyclonal activation of human memory B-cells. Science 2002, 298, 2199-2202. [CrossRef] [PubMed]

51. Amanna, I.J.; Hammarlund, E.; Lewis, M.W.; Slifka, M.K. Impact of infection or vaccination on preexisting serological memory. Hum. Immunol. 2012, 73, 1082-1086. [CrossRef] 